\title{
The Decrease of Lung Eosinophil Following Zinc Supplementation in Mouse Models of Respiratory Allergic Inflammation
}

\author{
Zinc Supplementation on Respiratory Allergic Diseases
}

\author{
Agatha Magistalia Cahiadewi ${ }^{1}$, Yanuar Iman Santosa ${ }^{2}$, Anna Mailasari Kumala Dewi ${ }^{2}$ and Suprihati ${ }^{2}$ \\ 1. Faculty of Medicine.Diponegoro University, Semarang 50236, Indonesia \\ 2. Ear Nose and Throat Department, Faculty of Medicine, Diponegoro University, Semarang 50236, Indonesia
}

\begin{abstract}
Background: United airway disease, a comorbid of allergic rhinitis and asthma, leads to the accumulation of toxic eosinophil in the lung parenchyma as a result of allergic reaction. Ovalbumin (OVA) sets off a condition of eosinophilia in the respiratory tract. Zinc supplementations are proposed to decrease the amount of eosinophil in the lung parenchyma due to its cytoprotective, anti-inflammation and antioxidant activity. Objectives: Proving the effects of the zinc supplementation on the number of eosinophil in the lung histopathology preparations of the BALB/c mice that were sensitized with OVA. Method: A post-test only control group design was used, which consisted of eighteen female BALB/c mice divided into three groups: the negative control group (K1), positive control group with OVA sensitization (K2), and group of mice with OVA sensitization and $5 \mathrm{mg} / \mathrm{kg}$ body weight zinc supplementation $(\mathrm{P})$. The treatments were given for 30 days and then eosinophils in the lung histopathology preparations of the BALB/c mice were counted. Results: The mean eosinophil count in the negative control group (K1) was 0.48 , the positive control group (K2) was 2.12, and the group of mice with OVA sensitization and $5 \mathrm{mg} / \mathrm{kg}$ body weight zinc supplementation (P) was 0.76. The number of eosinophil in the lungs in the K2 group was significantly higher than the K1 group $(p=0.000)$ and the $\mathrm{P}$ group was significantly lower than K2 group in ANOVA Test followed by Post Hoc Test $(p=0.001)$. Conclusion: The zinc supplementation reduces the number of eosinophil in the lungs tissue of the BALB/c mice that were sensitized with OVA.
\end{abstract}

Key words: Zinc, ovalbumin, eosinophil, allergic rhinitis, asthma.

\section{Introduction}

Type I hypersensitivity is an allergic reaction associated with specific immunoglobulin E (IgE) in atopic patients. It might be manifested as allergic rhinitis on the upper respiratory tract and asthma in the lower respiratory tract. The number of allergic rhinitis-asthma comorbidity is estimated on 200 million of 600 million people suffering from allergic rhinitis, thus known as rhino bronchitis or united airway disease [1-3]. The chronic inflammation of the respiratory tract sets off the response of inflammatory mediators i.e. IL-4, IL-13, IL-5 and eosinophilia

Corresponding author: Suprihati, Prof., PhD, MSc, ENT Surgeon, research fields: ENT allergy and infection. which will be manifested as allergic reaction. Eosinophils contain toxic proteins that can damage organ tissues $[4,5]$. Ovalbumin (OVA), one of the specific allergens in egg whites, causes Th1-Th2 imbalance by means of increasing Th2 activation. In conditions of predominantly Th2 cells, there will be an increase in the rate of specific IgE production and mast cell degranulation which will release inflammatory cells such as eosinophilia in the lung parenchyma [2, 3].

Zinc is an essential micronutrient which is also an antioxidant and anti-inflammatory agent. Zinc on its labile form is found in the apical cytoplasmic epithelial respiratory tract, serves as a muccoprotectant and affects eosinophil, neutrophils and mast cells. Zinc supplementation may decrease the amount of 
eosinophils in the nasal mucosa and lung parenchyma associated with allergies in the respiratory tract $[6,7]$.

\section{Materials and Methods}

This study was conducted in the Biology Laboratory of the Faculty of Natural Sciences and Mathematics, State University of Semarang. Post test only control group experimental design was used. Eighteen BALB/C mice as the samples with the inclusion criteria of 6-8 weeks age, 20-25 grams of weight, active and healthy mice without any anatomical deformity were investigated. The sample which died before the data collection was excluded. This research was approved by the Faculty of Medicine Diponegoro University Medical Ethic Committee (EC No. 531/EC/2016).

The samples were divided into three groups; namely: the negative control group (K1), positive control group with OVA sensitization (K2) and treatment group with OVA sensitization and zinc supplementation (P). Each group contained six mice as recommended by the Research Guideline for Evaluating the Safety and Efficacy of Herbal Medicine from WHO.

The mice in $\mathrm{K} 1$ group were fed ad libitum without any further intervention, whereas the mice in the $\mathrm{K} 2$ group were given $10 \mu \mathrm{g}$ OVA and $2 \mathrm{mg} \mathrm{Al}(\mathrm{OH})_{3}$ in $0.2 \mathrm{~mL}$ normal saline on days $0,7,14$ through intra peritoneal injections and inhalation of 1\% OVA on days 19, 22 for 30 minutes each day. The mice in the $\mathrm{P}$ group were given similar intervention with group $\mathrm{K} 2$ and $0.1 \mathrm{mg}$ zinc supplementation in $0.5 \mathrm{~mL}$ solvent through probe on days 15,30 . On day 31 , termination was performed on all samples by dislocation of atlanto-occipital joint, lung samples were collected and Hematoxylin-eosin (HE) staining was done. A $400 \times$ magnification on the lung histopathology preparations for eosinophil number count was used.

The analysis of the data was performed using a computer software. The data distribution was tested using the Saphiro-Wilk Test and Lavene homogenicity test. Since the data distribution was normal, the difference of the eosinophil number test was done using the one-way ANOVA with Post Hoc Bonferroni.

\section{Results}

Out of the eighteen samples, two samples, from the $\mathrm{K} 1$ group and the K2 group, died and were excluded from the research. The distribution of eosinophil number on lung parenchyma in the three groups was presented in Table 1. Using One-way ANOVA with Bonferroni Post Hoc analysis, the result showed significant differences $(p<0.001)$ of the eosinophil numbers among the groups. The result was presented in Table 2.

The eosinophil number in the $\mathrm{K} 2$ group (mean = $2.12 \pm 0.75)$ was significantly higher $(p<0.001)$ than the $\mathrm{K} 1$ group $($ mean $=0.48 \pm 0.1$ ). The eosinophil number in the $\mathrm{P}$ group (mean $=0.76 \pm 0.15$ ) was significantly lower $(p<0.001)$ than the $\mathrm{K} 2$ group (mean $=2.12 \pm 0.75$ ).

The results of lung samples which were collected and stained by Hematoxylin-eosin (HE) were presented in $400 \mathrm{x}$ magnification on the lung histopathology preparations which can be seen in figures 1, 2 and 3 .

Table 1 Distribution of eosinophil number on lung parenchyma.

\begin{tabular}{llll}
\hline \multicolumn{3}{c}{ Group of mice } \\
\hline Group & K1 & K2 & P \\
\hline $\mathrm{N}$ & 5 & 5 & 6 \\
$\mathrm{Mean}$ & 0.48 & 2.12 & 0.76 \\
$\mathrm{SD}$ & 0.10 & 0.75 & 0.15 \\
Median & 0.40 & 1.8 & 0.80 \\
Minimum & 0.40 & 1.6 & 0.60 \\
Maximum & 0.60 & 3.4 & 1.00 \\
\hline
\end{tabular}



Mouse Models of Respiratory Allergic Inflammation

Table 2 One-way ANOVA with Bonferroni Post hoc analysis result.

\begin{tabular}{lll}
\hline Group & K1 & K2 \\
\hline K1 & - & $0.001^{*}$ \\
$\mathrm{P}($ Zink $)$ & $0.023^{*}$ & $0.001^{*}$ \\
\hline
\end{tabular}

* Significant different between groups using One-way ANOVA with Bonferroni Post hoc analysis.

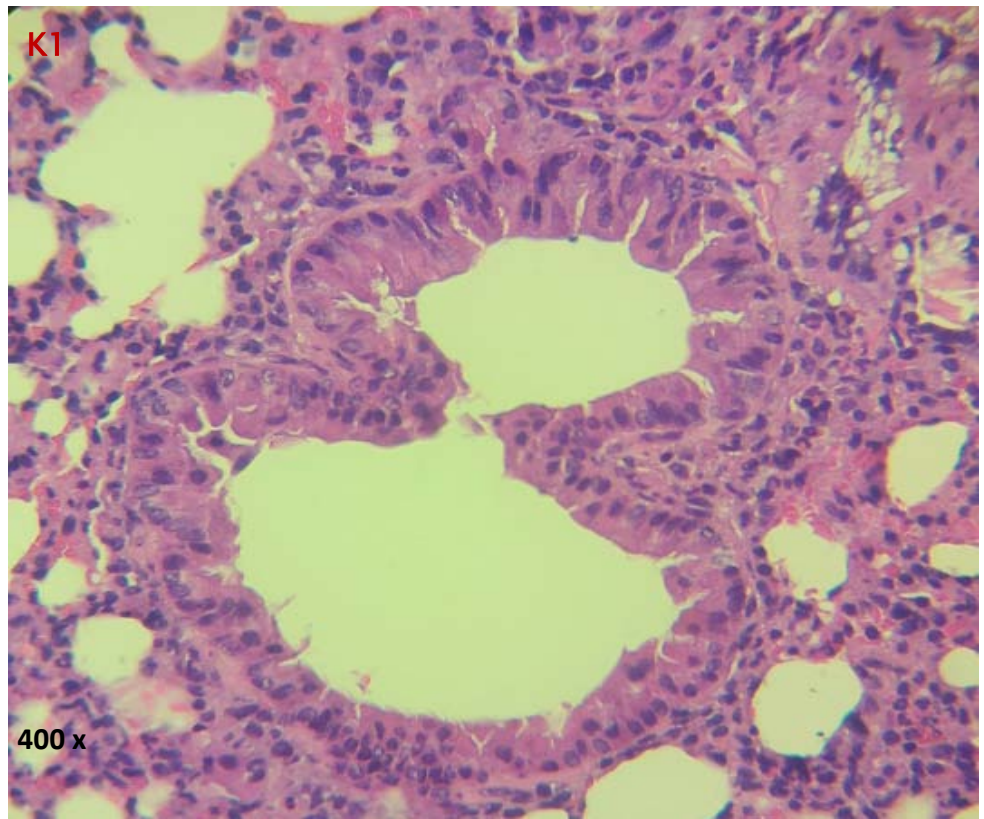

Fig. 1 Histopathology examination of the K1 group (magnification $400 \times$ ).

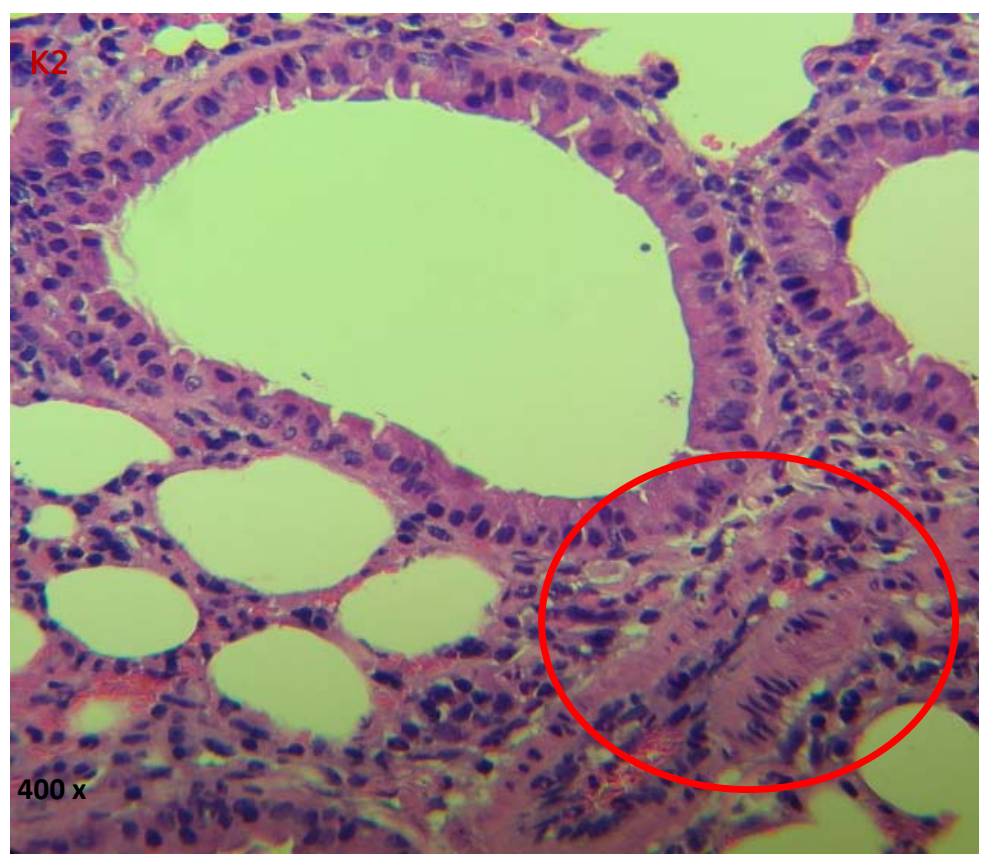

Fig. 2 Histopathology examination of the K2 group (magnification $400 \times$ ). 


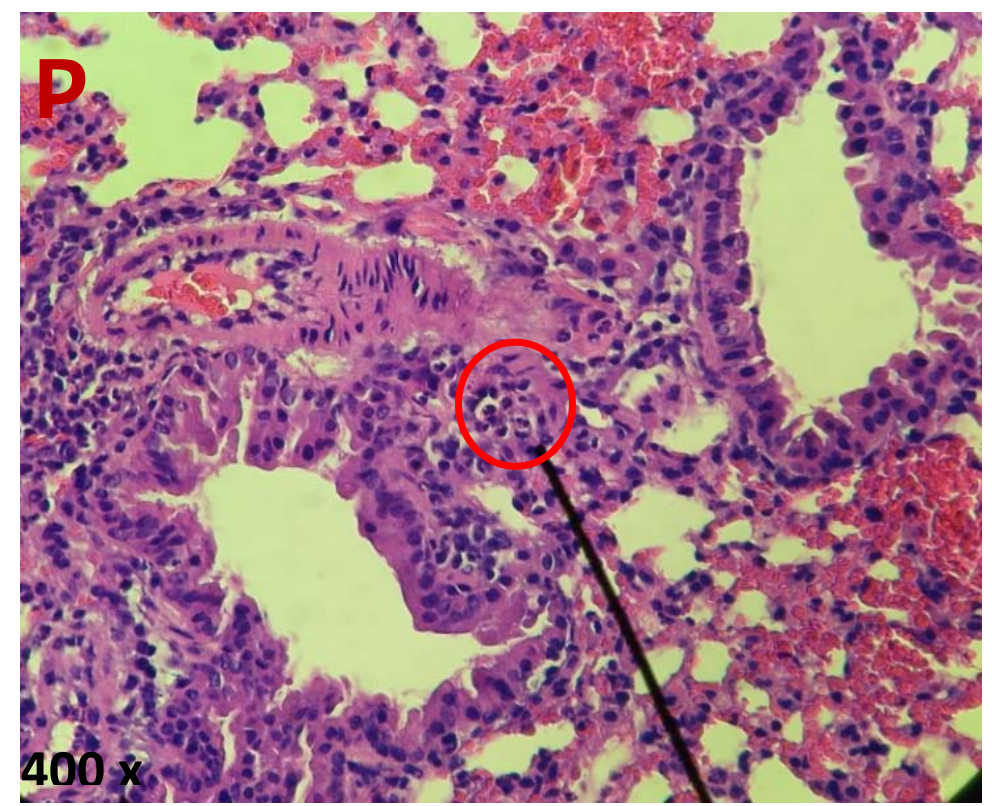

Fig. 3 Histopathology examination of the P group (magnification $400 \times$ ).

\section{Discussion}

The imbalance of Th1-Th2 with a dominance of humoral immunity (Th2) led to the release of various cytokines and inflammatory mediators that mediated allergic reactions, namely IL-4, IL-5, IL-13 and the activation of B lymphocyte cells to produce specific IgE antibodies [8]. The interaction of allergens through specific IgE attached to sensitized mast cells triggered degranulation which released histamine in the early-phase allergic reactions and eosinophil in the late-phase allergic reactions. The accumulation of eosinophil as a predominant cell to the lung tissue in allergic respiratory tract is affected by ICAM-1 and VCAM-1. The recruitment process of eosinophils leads to the release of eosinophil granule proteins which have a toxic effect on tissue inflammation, which is also influenced by IL-5 [9-11].

\subsection{Ovalbumin Sensitization Against the Number of Eosinophil in the Lungs}

Ovalbumin (OVA) as egg protein allergens can be quite effective in developing a mouse model of allergy. OVA can be implemented through local and systemic methods in an acute or chronic period that can increase specific IgE levels and accumulation of eosinophils [11]. The sensitization of OVA in this study successfully triggered inflammations in the respiratory tract of the allergy animal models $[9,11]$. Sensitization OVA by intra-peritoneal injection on days 0 and 14, followed by inhalations of OVA for twenty minutes with a frequency of three times a week for six weeks providing the inflammatory responses with infiltration of inflammatory cells and eosinophil were significantly higher in the group of OVA than in the negative control group ( $p=0.029)$ [12, 13].

The supplementation of $\mathrm{Al}(\mathrm{OH})_{3}$ as an adjuvant of OVA sensitization improved the dominance of Th2 lymphocytes and let the sensitized mast cells be produced freely; hence, it can trigger an allergic reaction in a shorter time. The OVA sensitization with an adjuvant could produce higher levels of OVA-specific IgE antibodies $(67 \pm 11)$ than the OVA sensitization without adjuvant $(41 \pm 3.6)$ [14].

The selection of the female BALB/c mice strain in developing allergy mouse model was selected based on the higher degree of sensitivity in order to activate dominancy of Th2 lymphocytes compared to other strains. The OVA sensitization in the BALB/c mice, which results in a significant difference between the 
levels of mucus secretion of goblet cells and levels of OVA-specific IgE antibodies, are higher than the OVA sensitization in mice C57BL [6, 11-14].

In this study, the level of specific IgE antibody and IFN- $\gamma$ pre- and post-treatment of OVA sensitization were not assessed and compared. The sensitization was only performed in an acute period so the histopathology change of respiratory epithelium due to chronic inflammation was not obtainable $[10,11]$. Further research is needed in regard to the duration and type of OVA sensitization as well as the more specific effects on the allergy of respiratory tract.

\subsection{Effect of Zinc Supplementation on the Number of Eosinophil in the Lungs}

Zink as an essential micronutrient is shown to improve the clinical outcomes and quality of life in patients with allergic rhinitis [15]. Zink in the free form or labile-zinc is widely available in the apical cytoplasm of epithelial respiratory tract cell and acts as cyto-protectant in preventing epithelial damage caused by free radicals and inflammatory mediators [16]. Allergic reactions on the respiratory tract might lead to conditions of zinc deficiency which possibly reduce the productions of INF- $\gamma$ and IL-2 as the activators of the Th1 lymphocytes, but zinc deficiency would not affect the productions of IL-4, IL-6, and IL-10 as the activators of the Th2 lymphocytes [17]. Nevertheless, these conditions could still lead to the dominance of humoral immunity (Th2) resulting in an increase in IgE antibodies and the accumulation of eosinophil as an inflammatory allergic response $[9,10$, 18].

Zinc deficiency due to respiratory allergies affects the zinc transporter protein that could reduce or increase the uptake of labile-zinc efflux. A significant reduction of ZnT4 m-RNA and ZIP4 was found in the allergic mice. Moreover, vesicular zinc cannot reach the apical cytoplasm of epithelial and failed to form a $\mathrm{Cu} / \mathrm{Zn}$ SOD as an antioxidant function of zink [6]. An allergic inflammation reaction can also increase hyper secretion of zinc in order to function as anti-apoptosis. Excessive zinc loss due to the damage of the apical portion of the cytoplasm, and vulnerability to ROS (reactive oxygen species) cause some zinc deficiency conditions which would exacerbate the allergic inflammatory reactions $[7,16]$.

This research obtained that zinc supplementation could reduce the number of eosinophil in allergic respiratory tract. Zinc supplementation is proven to increase the production of INF- $\gamma$ and IL-2 in allergic respiratory tract. Previous work by Aydemir et al. reported the results of IFN- $\gamma$ mRNA after the supplementation of $\mathrm{ZnSO}_{4}$ were significantly higher than the placebo, therefore can prevent the emergence of various inflammatory mediators, including eosinophil, as a result of an imbalance of Th1-Th2 [19].

Moreover in this study, single dose of zinc supplementation was given instead of grading dose. Therefore, data of the optimum dose and zinc toxicity level were not obtainable. The duration of zinc supplementation treatment was limited that it is difficult to analyze the exact time of eosinophil count maximum decrease. Therefore, further research on respiratory tract allergy is needed to examine the more varied dosage of zinc supplementation, the toxicity and the most effective duration of its administration.

\section{Conclusion}

Ovalbumin (OVA) sensitization through intra peritoneal injection and inhalation on BALB/c mice could raise the eosinophil number in lung tissue. Supplementation of zinc on OVA sensitized BALB/c mice could decrease the eosinophil number in the lung tissue.

\section{Acknowledgments}

We thank our colleagues from Biology Laboratory of the Faculty of Nature Science and Mathematics, State University of Semarang and Anatomical Pathology of Kariadi General Hospital Semarang who 
provided insight and expertise that greatly assisted the research.

\section{References}

[1] Baratawidjaja, K. G., and Rengganis, I. 2009. "Rinitis Alergi.” In Alergi Dasar (1st ed.). Jakarta: Interna Publishing, 125-56.

[2] Mandhane, S. N., Shah, J. H., and Thennati, R. 2011. "Allergic Rhinitis: An Update on Disease, Present Treatments and Future Prospects.” Int Immunopharmacol 11 (11): 1646-62

[3] Zheng, T., Yu, J., Oh, M. H., and Zhu, Z. 2011. “The Atopic March: Progression from Atopic Dermatitis to Allergic Rhinitis and Asthma.” Allergy Asthma Immunol Res. 3 (2): 67-73.

[4] Rupa, P., Schnarr, L., and Mine, Y. 2015. "Effect of Heat Denaturation of Egg Whithare Proteins Ovalbumin and Ovomucoid on CD4 + T Cell Cytokine Production and Human Mast Cell Histamine Production.” J Funct Foods 18: 28-34.

[5] Nials, A. T., and Uddin, S. 2008. "Mouse Models of Allergic Asthma: Acute and Chronic Allergen Challenge." Dis Model Mech. 1 (4-5): 213-20.

[6] Zalewski, P. D., Truong-Tran, A. Q., Grosser, D., Jayaram, L., Murgia, C., and Ruffin, R. E. 2005. “Zinc Metabolism in Airway Epithelium and Airway Inflammation: Basic Mechanisms and Clinical Targets. A Review.” Pharmacol Ther. 105 (2): 127-49.

[7] Morgan, C. I., Ledford, J. R., Zhou, P., and Page, K. 2011. "Zinc Supplementation Alters Airway Inflammation and Airway Hyperresponsiveness to a Common Allergen.” pp. 1-10.

[8] Salib, R. J., Drake-Lee, A., and Howarth, P. H. 2003. “Allergic Rhinitis: Past, Present and the Future." Clin Otolaryngol Allied Sci. 28 (4): 291-303.

[9] Kiecolt-Glaser, J. K., Heffner, K. L., Glaser, R., Malarkey, W. B., Porter, K., Atkinson, C., et al. 2009. "How Stress and Anxiety Can Alter Immediate and Late Phase Skin Test Responses in Allergic Rhinitis.” Psychoneuroendocrinology 34 (5): 670-80.
[10] Gangwar, R. S., Friedman, S., Seaf, M., and Levi-Schaffer, F. 2015. "Mast Cells and Eosinophils in Allergy: Close Friends or Just Neighbors.” Eur $J$ Pharmacol. 778: 1-7.

[11] Wyss, D., Bonneau, O., and Trifilieff, A. 2005. "Mast Cell Involvement in the Adenosine Mediated Airway Hyper-Reactivity in a Murine Model of Ovalbumin-Induced Lung Inflammation.” $\mathrm{Br} J$ Pharmacol. 145: 845-52.

[12] Lee, E. J., Song, M. J., and Kwon, H. S. 2012. “Oral Administration of Fermented Red Gingseng Suppresed Ovalbumin-Induced Allergic Responses in Female BALB/c Mice.” Phytomed. 896-903.

[13] Barlianto, W., and Chandra, K. 2009. "Pengembangan model mencit alergi dengan paparan kronik ovalbumin.” Jur K Brawijaya 25: 1-5.

[14] Conrad, M. L., and Yildirim, A. O. 2009. "Comparison of Adjuvant and Adjuvant-Free Murine Experimental Asthma Models.” Clin Exp Allergy 39 (8): 1246-54.

[15] Setyorini, D. 2014. "Pengaruh suplementasi zink pada perbaikan gejala klinis dan kualitas hidup penderita rinitis alergi persisten sedang berat.” Thesis, Semarang: Fakultas Kedokteran Universitas Diponegoro.

[16] Murgia, C., Grosser, D., Truong-tran, A. Q., Roscioli, E., Michalcsyk, A., Ackland, M. L., Stoltenberg, M., et al. 2011. “Apical Localization of Zinc Transporter ZnT4 in Human Airway Epithelial Cells and Its Loss in a Murine Model of Allergic Airway Inflammation.” Nutrients 3 (11): 910-28.

[17] Lu, H., Xin, Y., Tang, Y., and Shao, G. 2012. "Zinc Suppressed the Airway Inflammation in Asthmatic Rats: Effects of Zinc on Generation of Eotaxin, MCP-1, IL-8, IL-4, and IFN- $\gamma$.” Biol Trace Elem Res. 150 (1-3): 314-21.

[18] Richter, M., and Bonneau, R. 2003. “Zinc Status Modulates Bronchopulmonary Eosinophil Infiltration in a Murine Model of Allergic Inflammation.” Ches. 123: 446S.

[19] Aydemir, T. B., Liuzzi, J. P., McClellan, S., and Cousins, R. J. 2009. "Zinc Transporter ZIP8 (SLC39A8) and Zinc Influence INF- $\gamma$ Expression in Activated Human T Cells.” J. Leukoc. Biol. 86 (2): 337-48. 